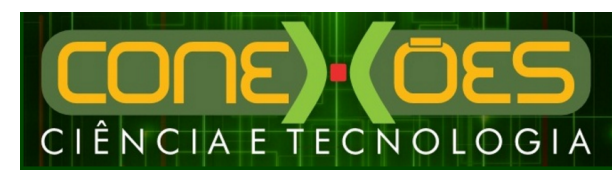

CRITÉRIOS DE SUSTENTABILIDADE AMBIENTAL NA ADMINISTRAÇÃO PÚBLICA FEDERAL: VANTAGENS E DESVANTAGENS COM BASE NA INSTRUÇÃO NORMATIVA 01/2010

\title{
CRITÉRIOS DE SUSTENTABILIDADE AMBIENTAL NA ADMINISTRAÇÃO PÚBLICA FEDERAL: VANTAGENS E DESVANTAGENS COM BASE NA INSTRUÇÃO NORMATIVA 01/2010
}

\author{
KAMYle Braga SoARES, IVANDIR dA Silva BARroso, \\ Francisca Maria Muniz Deusdará, Sílvia Helena Oliveira Rodrigues \\ Instituto Federal de Educação, Ciência e Tecnologia do Ceará (IFCE), \\ Campus de Fortaleza \\ <kamylebraga@yahoo.com.br>. <ivandir@ifce.edu.br>
<nena@ifce.edu.br>.<silvia@ifce.edu.br>
}

DOI: 10.21439/conexoes.v11i3.899

\begin{abstract}
Resumo. Busca-se compreender os critérios de sustentabilidade ambiental na Administração Pública, apresentando possíveis vantagens e desvantagens na utilização de tais recursos. Em relação aos aspectos metodológicos, as hipóteses são investigadas por meio de pesquisa bibliográfica e de estudo documental através de projetos, relatórios, leis, resoluções, instruções normativas, pesquisa on-line, dentre outros que tratam sobre o tema. Quanto aos objetivos metodológicos, a pesquisa é descritiva, classificando, explicando e interpretando os fatos, descrevendo os fenômenos sobre o tema, sua natureza, suas características e relações com outros fatos; e exploratória, definindo objetivos e buscando maiores informações sobre o assunto pesquisado, procurando aprimorar ideias, formular hipóteses e embasá-las de forma a aperfeiçoar a pesquisa. Assim, verificando-se que o Estado já apresentou alguns avanços nos procedimentos das compras públicas, desde a promulgação da Constituição Federal, no que concerne à legislação ligada a sustentabilidade ambiental, buscou-se entender quais os critérios aplicados nas compras públicas e demonstrando, ao final, que existem vantagens e desvantagens na utilização dos critérios de sustentabilidade ambiental nas compras públicas; acrescentando-se que, devido a alguns obstáculos, tais requisitos não se encontram, ainda, plenamente estabelecidos.
\end{abstract}

Palavras-chaves: Administração Pública. Licitações Públicas. Instrução Normativa 01/2010. Critérios de sustentabilidade ambiental.

\begin{abstract}
We seek to understand the environmental sustainability criteria in Public Administration, by presenting possible advantages and disadvantages in the use of such resources. With regard to methodological aspects, the hypotheses are investigated by means of a bibliographic research and documentary study through projects, reports, laws, resolutions, normative instructions, online research, among other means dealing with the subject. As for the methodological objectives, the research is descriptive, by classifying, explaining, and interpreting the facts, describing the phenomena on the subject, their nature, characteristics, and relations with other facts; and exploratory, by setting goals, and seeking more information about the issue researched, seeking to improve ideas, formulate hypotheses, and base them in order to refine the research. Thus, by verifying that the State has already advanced in public purchase procedures, since the promulgation of the Federal Constitution, concerning the legislation related to environmental sustainability, we have tried to understand what criteria are used in public purchases, and by demonstrating, at the end, there are advantages and disadvantages in the use of environmental sustainability criteria in public purchases; by adding that, due to some obstacles, such requirements are not yet fully established.
\end{abstract}

Keywords: Public Administration. Public Bids. Normative Instruction 01/2010. Environmental sustainability criteria. 


\section{INTRODUÇÃO}

Na administração da coisa pública, o Poder Público deve desenvolver suas atividades sempre objetivando atender às necessidades coletivas e alcançar o bem comum, em obediência aos ditames da lei e aos princípios constitucionais. Com a aquisição de bens e alienações, ou contratações de obras ou de serviços não é diferente. Esses atos administrativos, necessários para o funcionamento do Estado, devem igualmente cumprir as normas e princípios que regulam a Administração Pública.

Assim, foi instituído um procedimento administrativo para regular as compras públicas. Esse procedimento, denominado de licitações públicas, tem por base legal o art. 37, inc. XXI, da Constituição Federal de 1988; cujo objetivo principal é selecionar a proposta mais vantajosa para a Administração, ao mesmo tempo em que cumpre todos os princípios estabelecidos no caput desse artigo. Busca-se, assim, evitar que haja desvios de verbas públicas ou ofensa aos direitos dos administrados ao serem dados privilégios a um ou outro licitante.

Ademais, este artigo foi regulamentado pela Lei 8.666, de 21 de junho de 1993, que instituiu os procedimentos para as licitações e para os contratos da Administração Pública e que fixou, entre outras coisas, as modalidades de licitação. Em 2002, com o advento da Lei 10.520/02, surgiu uma nova modalidade de licitação - o pregão. Essa nova modalidade licitatória foi dividida pela legislação em duas espécies: o pregão presencial (Lei 10.520/02 e Decreto 3.555/00) e o pregão eletrônico (Decreto 5.450/05). Destacando-se como principal característica do pregão a inversão das fases de aceitação e habilitação previstas na Lei 8.666/93.

Essa inversão facilitou a análise dos documentos, diminuiu a burocracia, agilizou o processo e reduziu consideravelmente a papelada anexada ao mesmo. Além disso, a forma eletrônica do pregão possui as mesmas regras do pregão presencial acrescida de algumas vantagens. Uma delas é a diminuição das distâncias que o pregão eletrônico proporcionou, não sendo mais necessária a presença física do pregoeiro nem dos demais participantes do certame devido ao uso dos sistemas eletrônicos.

Posteriormente, outro assunto que passou a ser objeto de preocupações por parte dos administradores públicos foi a questão ambiental nas aquisições de bens e na contratação das obras e dos serviços. A Constituinte Originária já havia alertado acerca da importância do tema no art. 225, da Carta Magna, demonstrando que tal questão já há algum tempo era objeto de inquietação no território nacional. Em âmbito mundial, o assunto foi tratado pela primeira vez em 1987 no Relató- rio Brudtland, elaborado pela Comissão Mundial sobre Meio Ambiente e Desenvolvimento; ressaltando-se que o conceito de sustentabilidade e a importância da proteção ambiental somente ganharam destaque mundial em 2002, na Cúpula Mundial sobre Desenvolvimento Sustentável de Joanesburgo.

Assim, na tentativa de se adaptar a essa nova realidade, buscou-se modificar o conceito de licitação para que se ajustasse às transformações que ocorreram no âmbito da preservação ambiental, adequando os atos administrativos às novas necessidades e interesses da sociedade e buscando aperfeiçoar os procedimentos licitatórios nesse aspecto. Somou-se, desse modo, ao conceito de compras públicas a ideia de aquisições de bens e realização de obras e de serviços sustentáveis, ou seja, o Estado passou a se preocupar também com a preservação do meio ambiente.

Foi nesse sentido que em 19 de janeiro de 2010, o Ministério do Planejamento, Orçamento e Gestão MPOG baixou a Instrução Normativa 01 (IN 01/2010) em cumprimento ao disposto no art. 28, do anexo I, do Decreto $n^{0} 7.063 / 2010$. A IN 01/2010 dispõe sobre critérios de sustentabilidade ambiental na aquisição de bens, contratação de serviços ou obras pela Administração Pública Federal e explicita em seu art. $1^{\circ}$ que:

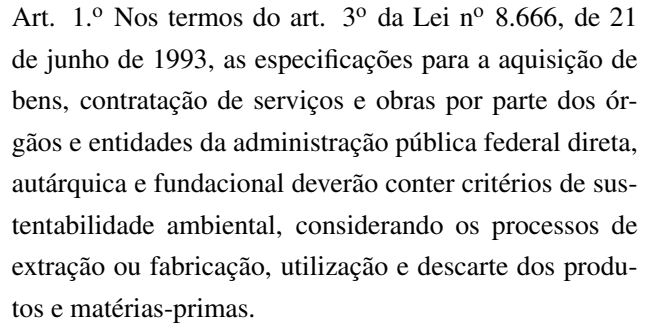

Tem-se, então, como objetivo do presente estudo analisar as aquisições de bens e a contratação de obras com critérios de sustentabilidade ambiental no âmbito da Administração Pública Federal, com base na Instrução Normativa 01/2010; descrevendo quais os requisitos necessários para a realização de licitações baseadas no conceito de sustentabilidade ambiental da IN 01/2010; verificando, ainda, as possíveis vantagens e desvantagens da utilização de práticas de consumo sustentável.

Em relação aos aspectos metodológicos, as hipóteses são investigadas por meio de pesquisa bibliográfica e de estudo documental através de projetos, relatórios, leis, resoluções, instruções normativas, pesquisa on-line, dentre outros que tratam sobre o tema. Quanto aos objetivos metodológicos, a pesquisa é descritiva, classificando, explicando e interpretando os fatos, descrevendo os fenômenos sobre o tema, sua natureza, suas 
CRITÉRIOS DE SUSTENTABILIDADE AMBIENTAL NA ADMINISTRAÇÃO PÚBLICA FEDERAL: VANTAGENS E DESVANTAGENS COM BASE NA INSTRUÇÃO NORMATIVA 01/2010

características e relações com outros fatos; e exploratória, definindo objetivos e buscando maiores informações sobre o assunto pesquisado, procurando aprimorar ideias, formular hipóteses e embasá-las de forma a aperfeiçoar a pesquisa.

\section{CONCEITOS DE LICITAÇÃO PÚBLICA SUS- TENTÁVEL}

A importância do conceito de desenvolvimento sustentável reside no fato de que o consumo dos recursos naturais do planeta aumenta a cada ano de forma assustadora, o que gera problemas ambientais. Os efeitos negativos desses problemas ambientais, ao longo do tempo, poderão comprometer o desenvolvimento e continuidade de todas as formas de vida no planeta, daí a apreensão com o tema. Ademais, a preocupação da Administração Pública com as questões ambientais, mais precisamente a sustentabilidade de seus atos, é relevante em face do dever do Estado de proteger o meio ambiente e zelar pela qualidade de vida e bem estar das gerações. Essa ideia encontra-se balizada no art. 225, da Constituição Federal de 1988, in verbis: "Todos têm direito ao meio ambiente ecologicamente equilibrado, bem de uso comum do povo e essencial à sadia qualidade de vida, impondo-se ao Poder Público e à coletividade o dever de defendê-lo e preservá-lo para as presentes e futuras gerações".

Assim, devido ao crescimento desses problemas ambientais e ao dever do Poder Público de proteger o meio ambiente, constatou-se a necessidade de mudança da realidade na qual a sociedade vive e a importância do desenvolvimento de políticas que viessem vinculadas a estratégias ambientais. Tais políticas buscariam cumprir as metas do planejamento do Estado sem, no entanto, prejudicar o bem estar e o direito à qualidade de vida das gerações futuras.

Desse modo, o governo passou a criar políticas que procuravam efetivar de modo prático o conceito de sustentabilidade nas compras de bens e na realização de obras pela Administração Pública. É o que Santos (2010a, p. 8) procura esclarecer na seguinte passagem: "[...] com o surgimento do conceito de desenvolvimento sustentável no contexto mundial, observase a tendência de gerar políticas que levem em conta os aspectos ambientais que geralmente comprometem também os aspectos sociais e econômicos.".

Assim, uma dessas estratégias políticas de preservação ambiental, criada pela Administração Pública, são as licitações públicas sustentáveis. Nelas são estabelecidos exigências ou requisitos de preservação ambiental ao mesmo tempo em que se realizam as compras necessárias ao funcionamento dos órgãos governamen- tais. Observa-se, ainda, que a mudança no interesse do setor público, passou da compra de produtos tradicionais, para produtos que afetem menos o meio ambiente; protegendo, portanto, o direito do cidadão ao meio ambiente ecologicamente equilibrado e à sadia qualidade de vida. É o que noticia o Ministério do Planejamento, Orçamento e Gestão - MPOG, por meio do Informativo Sustentável divulgado no sítio oficial de compras do governo federal (comprasnet), ao apresentar dados estatísticos que comprovam os avanços nas compras sustentáveis, declarando que:

As compras públicas sustentáveis feitas no primeiro trimestre de 2012 já representam 83\% das aquisições realizadas em 2011 nas chamadas "licitações sustentáveis". Na comparação desse período com o ano de 2010, verifica-se um acréscimo de $61 \%$ nas aquisições do governo federal. Até março de 2012, o valor dessas compras está em cerca de $\mathrm{R} \$ 12$ milhões de reais. De 2010 até o março de 2012, 735 unidades de órgãos governamentais usuários do SIASG - Comprasnet realizaram 1490 licitações utilizando itens de material do CATMAT classificados como sustentáveis, totalizando o valor de $\mathrm{R} \$$ 34.227.224,72 (trinta e quatro milhões, duzentos e vinte e sete centavos, duzentos e vinte e quatro reais e setenta e dois centavos (INFORMATIVO..., 2012).

Com tais atitudes, os governos influenciam os particulares, e até mesmo os mercados, e demonstram que é possível viver no planeta sem agredir sobremaneira os recursos naturais. Mas o que seria considerado sustentabilidade?

Segundo Ferreira (1986), o termo sustentabilidade deriva da palavra sustentar que entre suas muitas acepções significa "Impedir a ruína ou a queda de; amparar [...] proteger, favorecer, auxiliar". É nesse sentido que se encontra a ideia de sustentabilidade ou amparo ao meio ambiente, prevista no art. 225 da Constituição Federal/88, que dispõe o seguinte: "Todos têm direito ao meio ambiente ecologicamente equilibrado, bem de uso comum do povo e essencial à sadia qualidade de vida, impondo-se ao Poder Público e à coletividade o dever de defendê-lo e preservá-lo para as presentes e futuras gerações". Verificando-se, assim, que a preocupação com as questões ambientais é um dever de todos, tanto dos particulares quanto do Poder Público.

Já ALENCASTRO (2015 apud SACHS, 1993, p. 24-27) subdivide o conceito de sustentabilidade em cinco dimensões, quais sejam, social, econômica, eco- 
CRITÉRIOS DE SUSTENTABILIDADE AMBIENTAL NA ADMINISTRAÇÃO PÚBLICA FEDERAL: VANTAGENS E DESVANTAGENS COM BASE NA INSTRUÇÃO NORMATIVA 01/2010

lógica, espacial e cultural. Segundo referido autor, a dimensão social busca reduzir as desigualdades sociais e considerar as necessidades materiais e não materiais das pessoas. A dimensão econômica aborda a organização da vida material com base na sustentabilidade social e num modelo menos agressivo ao meio ambiente, aumentando a riqueza social e a produção por meio de alocação e gestão mais eficiente dos recursos. Por sua vez, a dimensão ecológica reafirma o uso dos recursos naturais com o mínimo de deterioração, preservando as fontes de recursos naturais e energéticos. A dimensão espacial determina uma distribuição mais equilibrada dos assentamentos humanos, ou seja, equilíbrio entre cidade e campo. E por fim, a dimensão cultural busca soluções adaptadas às especificidades de cada ecossistema, de cada cultura e local.

Para Cunha e Augustin (2014) o conceito de sustentabilidade surge como uma derivação do conceito da capacidade de suporte em ecologia, numa tentativa de compatibilizar o crescimento populacional humano com a preservação dos recursos. É nesse sentido o entendimento apresentado no Guia de compras públicas sustentáveis para Administração Federal que, ao tratar do tema, esclarece que sustentabilidade é a:

[...] necessidade de se garantir a disponibilidade dos recursos da Terra hoje, assim como para nossos descendentes, por meio de uma gestão que contemple a proteção ambiental, a justiça social e o desenvolvimento econômico equilibrado de nossas sociedades." (SANTOS 2010a p. 6, grifo do autor).

Mencionada cartilha acrescenta ainda, quanto à participação do governo, que seria “[...] necessário um esforço concentrado, no qual os governos desempenham um papel fundamental, como indutores de mudanças para o estabelecimento de um novo modelo de desenvolvimento, compatível com os limites do Planeta.".

Quanto ao conceito de licitações públicas, alguns estudiosos do tema o abordam sendo que Filho (2010, p. 11) afirma, tendo por base o explicitado no art. $3^{\circ}$ da Lei 8.666/93, que o procedimento administrativo chamado Licitação destina-se “[...] a selecionar, segundo critérios objetivos predeterminados, a proposta de contratação mais vantajosa para a Administração, assegurandose a ampla participação dos interessados e o seu tratamento isonômico, com observância de todos os requisitos legais exigidos.".

Já para Melo (2010, p. 524) licitação é:

[...] um certame que as entidades governamentais devem promover e no qual abrem disputa entre interessados em com elas travar determinadas relações de conteúdo patri- monial, para escolher a proposta mais vantajosa às conveniências públicas. Estriba-se na ideia de competição, a ser travada isonomicamente entre os que preenchem os atributos e aptidões necessários ao bom cumprimento das obrigações que se propõem assumir. (grifo do autor).

E por licitações sustentáveis, entende-se como:

[...] a forma como o imenso poder de compra do governo pode ser usado para se obter progresso rápido no alcance de um modelo de desenvolvimento mais sustentável. Trata-se de usar o poder de compra para apoiar objetivos sociais, econômicos e ambientais mais amplos, de maneira a oferecer benefícios reais de longo prazo. É algo que as melhores empresas do setor privado já estão fazendo e que o setor privado espera do setor público. Também é algo que o público espera cada vez mais por ser realmente importante. Trata-se de como o setor público deveria estar gastando o dinheiro dos contribuintes. DIÁLOGO... 2010,

Por sua vez.Biderman et al. (2008, p. 21) acrescenta que:

[...] licitação sustentável é uma solução para integrar considerações ambientais e sociais em todos os estágios do processo da compra e contratação dos agentes públicos (de governo) com o objetivo de reduzir impactos à saúde humana, ao meio ambiente e aos direitos humanos. A licitação sustentável permite o atendimento das necessidades específicas dos consumidores finais por meio da compra do produto que oferece o maior número de benefícios para o ambiente e a sociedade.

Mas o que pode ser considerado produto sustentável? Como o tema é relativamente novo não existe um conceito preciso e estável que esclareça o que poderia ser considerado produto sustentável, mas alguns estudiosos já se arriscam no sentido de apresentar uma noção a respeito. É, nesse sentido, que o Guia de compras públicas sustentáveis para Administração Federal (SANTOS, 2010b, p. 59) produz a seguinte concepção sobre o que seriam considerados produtos sustentáveis: Alguns produtos podem ser considerados sustentáveis
por gerarem menos perdas, por serem recicláveis ou mais
duráveis. Outros produtos são sustentáveis porque con-
têm menos substâncias prejudiciais ou tóxicas ou por-
que o processo de sua geração consome menos energia.
Para decidir qual produto é preferível em termos ambi-
entais, os cientistas consideram necessário sempre fazer
uma comparação dos impactos ambientais dos produtos
através da análise de seu ciclo de vida. A ação do ciclo de
vida leva em conta o impacto ambiental do produto em 
CRITÉRIOS DE SUSTENTABILIDADE AMBIENTAL NA ADMINISTRAÇÃO PÚBLICA FEDERAL: VANTAGENS E DESVANTAGENS COM BASE NA INSTRUÇÃO NORMATIVA 01/2010

todos os seus estágios, desde o nascimento, ou berço (ex-

tração do material/matéria-prima) ao túmulo (disposição

final), com o propósito de minimizar o dano ambiental.

Como se observa, nem o Guia criado para orientar a Administração consegue definir de forma clara o que seriam produtos sustentáveis. O que ele oferece é um procedimento conhecido como Avaliação do Ciclo de Vida (ou Life-Cycle Assessment - LCA como é conhecido).

O LCA possibilita a avaliação dos impactos ambientais dos produtos por meio da análise dos benefícios ambientais capazes de serem alcançados e das melhorias que podem ser realizadas na estrutura e desempenho desses produtos, sendo ao final comparada às compatibilidades ambientais deles com as dos concorrentes. Somente depois dessas fases poder-se-ia escolher um produto que atendesse de forma mais eficiência ao conceito de sustentabilidade. Assim, esse procedimento identifica os bens que geram menor perda, por serem recicláveis ou mais duráveis, além de verificar outros aspectos ambientais e impactos dos produtos, podendo dessa forma classificá-los como sustentáveis. Entretanto, apesar de na teoria o LCA ser um método criativo e até eficiente da análise desses produtos, ele não pode ser utilizado, pois " [....] ainda não estão disponíveis estudos suficientes e nem há acordo manifesto sobre as metodologias de análise do ciclo de vida dos produtos. No Brasil, poucos estudiosos dedicam-se à matéria, portanto, temos informação insuficiente para o uso desse enfoque em sua totalidade." (SANTOS, 2010b, p. 60). Dessa maneira, constata-se que ainda não há uma definição acerca do que pode ser considerado produto sustentável.

Portanto, a existência de um produto que cumpra apenas um critério de preservação ambiental já pode ser considerada suficiente para classificá-lo como sustentável, visto que o desenvolvimento atual do mercado de produtos sustentáveis não comporta requisitos que limitem a participação dos interessados, sob pena de tornar a licitação deserta ou fracassada, ou ferir os princípios que regem as compras públicas.

Desse modo, busca-se nortear a implantação de critérios de sustentabilidade nas licitações realizadas pelo Governo Federal por meio da IN 01/2010, baixada pelo Ministério do Planejamento, Orçamento e Gestão MPOG, a qual se analisará no item seguinte.

\section{CRITÉRIOS DE SUSTENTABILIDADE DA INSTRUÇÃO NORMATIVA 01/2010}

A Instrução Normativa 01/2010 do MPOG orienta as compras públicas quanto ao atendimento dos requi- sitos de sustentabilidade ambiental. Prevendo, inicialmente, em seu art. $1^{\circ}$ que as especificações para a aquisição de bens, contratação de serviços e obras por parte dos órgãos e entidades da administração pública federal direta, autárquica e fundacional deverão conter critérios de sustentabilidade ambiental, considerados os processos de extração ou fabricação, utilização e descarte dos produtos e matérias-primas; sem, contudo, desrespeitar os termos do art. $3^{\circ}$ da Lei $n^{\circ} 8.666 / 93$.

Ademais, a mencionada norma estabelece que, para a realização de um certame com tais critérios, é preciso que o instrumento convocatório explique, de forma clara, que a aquisição de bens e contratação dos serviços e obras será acrescida de critérios de sustentabilidade ambiental. É imperativo observar, ainda, que a inclusão desses requisitos não deve restringir ou frustrar a competitividade na licitação $\left(\operatorname{art} .2^{\circ}\right.$ ).

Além disso, constata-se que o momento mais apropriado para a inclusão dos requisitos de sustentabilidade ambiental é o da especificação dos produtos ou o da elaboração do edital, quando são definidos os objetos que se desejam adquirir e os documentos que os licitantes devem apresentar. Observando-se que tais critérios devem ser objetivos, claros e precisos, não devem ferir os princípios do julgamento objetivo e da isonomia e nem causar a exclusão do concorrente que não os possua. É nesse sentido, o que prescreve o art. $3^{\circ}$ da IN 01/10, ao afirmar que: "Nas licitações que utilizem como critério de julgamento o tipo melhor técnica ou técnica e preço, deverão ser estabelecidos no edital critérios objetivos de sustentabilidade ambiental para a avaliação e classificação das propostas" (grifo nosso).

\subsection{Nas obras públicas}

Primeiramente, para a realização de obras e serviços de engenharia pela Administração Federal com critérios de sustentabilidade ambiental, é necessária a elaboração dos projetos básicos e executivos. Eles devem trazer, para atender tais critérios, exigências e especificações que visem à economia na manutenção e operacionalização das edificações, à redução do consumo de energia e água e à utilização de tecnologias e materiais que reduzam o impacto ambiental (art. $4^{\circ}$ ). É importante ressaltar que a preocupação com a análise dos impactos ambientais das obras já vem desde a Lei 8.666/93, que a prevê no art. 12, inc. VII. Todavia, esse artigo não esclarece quais impactos e critérios ambientais devem ser considerados. Assim, a Instrução Normativa 01/10 vem esclarecer esse ponto ao estabelecer nos incisos do art. $4^{\mathrm{o}}$ um rol exemplificativo e obrigatório das tecnologias e materiais que devem ser utilizados na realização das obras públicas, sobre os quais se discorre agora. 
CRITÉRIOS DE SUSTENTABILIDADE AMBIENTAL NA ADMINISTRAÇÃO PÚBLICA FEDERAL: VANTAGENS E DESVANTAGENS COM BASE NA INSTRUÇÃO NORMATIVA 01/2010

Os primeiros incisos do art. $4^{\circ}$ se referem às tecnologias ligadas à eficiência energética e buscam desenvolver métodos ou criar tecnologias para o uso da energia que proporcione maior eficiência e menor custo para a instituição; utilizando, por exemplo: 1) climatização natural (inc. I); 2) automação da iluminação do prédio, uso de sensores de presença, iluminação ambiental, iluminação tarefa e interruptores (inc. II); 3) utilização exclusiva de lâmpadas fluorescentes compactas ou tubulares de alto rendimento e de luminárias eficientes (inc. III); e 4) uso de energia solar, ou de outra energia limpa, para o aquecimento da água (inc. IV).

Quanto ao consumo de água, prescreve a IN 01/2010 que nas obras deverá existir um sistema de medição individualizado de consumo de água e energia, bem como a utilização de um sistema de reuso de água e de tratamento dos efluentes gerados. A água da chuva também deverá ser aproveitada, utilizando-se um sistema hidráulico que possibilite a captação, transporte, armazenamento e seu aproveitamento (incs. V, VI e VII). A água captada poderá ser utilizada, por exemplo, para aguar plantas, nos testes de impermeabilização de caixas d'água das obras, na preparação da argamassa, etc.

Referente à gestão de resíduos, o inc. VIII descreve que deverão ser utilizados nas construções materiais que sejam reciclados, reutilizados e biodegradáveis, e que reduzam a necessidade de manutenção. Nesse sentido, o $\S 2^{\circ}$ indica que os fornecedores deverão observar na elaboração do Projeto de Gerenciamento de Resíduos da Construção Civil - PGRCC, estruturado em conformidade com o modelo especificado pelos órgãos competentes, as condições determinadas pelo Conselho Nacional do Meio Ambiente - CONAMA por meio da resolução no 307/02. Descartando-se, dessa maneira, adequadamente os resíduos da construção civil em aterros sanitários ou em usinas de tratamento de lixo.

Ainda com relação aos resíduos da construção civil, especifica o $\S 3^{\circ}$, do art. $4^{\circ}$, da Instrução Normativa 01/2010 que:

$\S 3^{\circ}$ Os instrumentos convocatórios e contratos de obras e serviços de engenharia deverão exigir o uso obrigatório de agregados reciclados nas obras contratadas, sempre que existir a oferta de agregados reciclados, capacidade de suprimento e custo inferior em relação aos agregados naturais, bem como o fiel cumprimento do PGRCC, sob pena de multa, estabelecendo, para efeitos de fiscalização, que todos os resíduos removidos deverão estar acompanhados de Controle de Transporte de Resíduos, em conformidade com as normas da Agência Brasileira de Normas Técnicas - ABNT, ABNT NBR nº 15.112 , $15.113,15.114,15.115$ e 15.116 , de 2004, disponibili- zando campo específico na planilha de composição dos custos.

Já o inc. IX da Instrução 01/2010 determina que a madeira utilizada na execução das obras e serviços de engenharia da Administração Pública Federal deverá ter sua origem comprovada, ou seja, sua extração e produção devem ser realizadas em conformidade com a lei e de preferência deve advir de empresas que utilizem práticas sustentáveis de extração e de fabricação da madeira, e de descarte das sobras, etc. Evita-se, assim, o emprego de madeira ilegal, advinda de reserva ambiental, e se dá prioridade às empresas que fazem reflorestamento, por exemplo.

Além disso, o $\S 1^{\circ}$ acrescenta que as autoridades públicas deverão priorizar o uso de mão de obra, de tecnologias, de matérias-primas e fornecimento de materiais locais; reiterando, dessa forma, o que prescrevia o art. 12 , inc. IV da Lei $\mathrm{n}^{\mathrm{o}} 8.666 / 93$. O intuito do legislador, ao reproduzir esse parágrafo, foi desenvolver o comércio local e gerar empregos na região, cumprindo ao objetivo fundamental disposto no art. $3^{\circ}$, inc. III da $\mathrm{CF} / 88$, qual seja: reduzir as desigualdades sociais e regionais. Igualmente, com essa atitude o meio ambiente será beneficiado, por exemplo, com a redução dos gases poluentes gerados no deslocamento dos materiais.

Por fim, estabelece o $\S 4^{\circ}$ que na elaboração dos projetos básico ou executivo devem sempre ser observadas as normas do Instituto Nacional de Metrologia, Normalização e Qualidade Industrial - INMETRO e as do ISO $n^{\circ} 14.000$. Determinando o $§ 5^{\circ}$ que o edital deverá exigir a comprovação de que o licitante adota práticas de descarte sustentável ou reciclagem dos bens que não puderem ser reutilizados, devendo também estabelecer diretrizes sobre a área de gestão ambiental dentro de empresas de bens, quando a contratação envolver a utilização de bens e a empresa for detentora da norma ISO 14000 .

\subsection{Nos bens e serviços}

Referente à aquisição de bens, o art. $5^{\circ}$ da Instrução Normativa 01/2010, traz um rol de critérios de sustentabilidade ambiental que poderão ser exigidos, no momento da compra, pelos órgãos e entidades da Administração Pública Federal direta, autárquica e fundacional. São eles: 1) que os bens sejam constituídos, no todo ou em parte, por materiais reciclados ou reutilizados, atóxicos e biodegradáveis, de acordo com as normas NBR 15448-1 e 15448-2 da ABNT; 2) que sejam observados os requisitos ambientais para obter certificação como produtos sustentáveis ou de menor impacto ambiental em relação aos seus similares expedida 
CRITÉRIOS DE SUSTENTABILIDADE AMBIENTAL NA ADMINISTRAÇÃO PÚBLICA FEDERAL: VANTAGENS E DESVANTAGENS COM BASE NA INSTRUÇÃO NORMATIVA 01/2010

pelo INMETRO; 3) que os bens preferencialmente sejam acondicionados individualmente e em embalagens feitas com materiais recicláveis, e que utilizem o menor volume possível; e 4) que não contenham substâncias perigosas em concentração acima da recomendada na diretiva Restriction of Certain Hazardous Substances RoHS. A RoHS, conhecida como lei dos sem chumbo, é uma diretiva europeia que proíbe o uso de substâncias perigosas nos processos de fabricação de produtos como o mercúrio, o chumbo, o cádmio, etc.

É importante ressaltar que o legislador deixa a critério do aplicador da norma utilizar ou não tais requisitos, já que estabelece um poder. Contudo, ao optar por incluí-los no instrumento convocatório, passam a ser obrigatórios e a vincular os participantes do certame. Portanto, a discricionariedade existe somente até o momento da inclusão das práticas de consumo responsável nas licitações públicas. Destaca-se, ainda, que a comprovação de que os requisitos ambientais são observados pelos licitantes pode ser feita mediante apresentação de certificação emitida por instituição pública oficial, instituição credenciada, ou por qualquer outro meio de prova que ateste que o bem fornecido cumpre com as exigências do edital $\left(\S 1^{\circ}\right.$, art. $\left.5^{\circ}\right)$, bem como pelo INMETRO (inc. II, art. $5^{\circ}$ ).

Em seguida, a Instrução Normativa disciplina que, caso inexista certificação que ateste a adequação da proposta aos requisitos de sustentabilidade estabelecidos no edital e selecionada a proposta vencedora, o órgão ou entidade contratante poderá realizar diligências, antes da assinatura do contrato, para verificar a adequação do produto às exigências edilícias, correndo as despesas por conta da licitante classificada. $\mathrm{O}$ edital deve também prevê que, caso não se confirme a adequação do produto, a proposta será desclassificada $\left(\S 2^{\circ}\right.$, art. $\left.5^{\circ}\right)$. Assim, possibilita-se com esse parágrafo uma adequação posterior dos fornecedores aos requisitos exigidos pela Administração; sem contrariar, dessa forma, os princípios da competitividade e da ampla participação.

De fato, a utilização desses critérios auxilia a Administração a elaborar especificações e justificativas adequadas para que o Poder Público compre produtos sustentáveis, que ajudam na preservação do meio ambiente, se considerado em relação aos seus similares, diminuindo assim a poluição no Planeta. Demonstrando, igualmente, que é possível um desenvolvimento contínuo e sustentável que afete minimamente os ecossistemas.

Quanto à inclusão de práticas sustentáveis nos editais para a contratação de serviços, o art. $6^{\circ}$ da Instrução Normativa traz um rol exemplificativo (de acordo com o seu parágrafo único) de atitudes que contribuem para a preservação do Planeta. Esse artigo estabelece entre outras coisas: 1) que sejam usados produtos de limpeza e conservação com obediência à classificação e especificações determinadas pela ANVISA; 2) que sejam adotadas medidas para evitar o desperdício de água; 3) que seja realizado treinamento dos empregados para redução de consumo de energia elétrica, de consumo de água e redução de produtos de resíduos sólidos com observância das normas ambientais vigentes, etc.

Referente aos bens ociosos ou inservíveis para o Estado estabelece o art. $7^{\circ}$ que a Administração deverá disponibilizar esses bens para doação a outros órgãos e entidades públicas de qualquer esfera da federação, conforme o Decreto 99.658/90, fazendo publicar uma relação desses bens em fórum disponível no portal eletrônico de contratações públicas do Governo Federal Comprasnet; que, além disso, passará a divulgar dados sobre planos e práticas de sustentabilidade ambiental na Administração Pública Federal (art. $9^{\circ}$ ).

Orienta, ainda, o $\S 1^{\circ}$ do art. $7^{\circ}$ que: "Antes de iniciar um processo de aquisição, os órgãos e entidades da Administração Pública Federal direta, autárquica e fundacional deverão verificar a disponibilidade e a vantagem de reutilização de bens, por meio de consulta ao fórum eletrônico de materiais ociosos." Assim, a Instrução Normativa comentada tenta incentivar o reaproveitamento dos bens. Já quanto aos bens ociosos de informática e automação, estabelece a Instrução Normativa que esses bens deverão obedecer à política de inclusão digital do Governo Federal, prevista em regulamentação específica $\left(\operatorname{art} .7^{\circ}, \S 2^{\circ}\right)$.

De todo o exposto, constata-se que, para realizar compras sustentáveis, o Poder Público deve racionalizar o uso dos materiais, reutilizar ou reciclar produtos, além de continuadamente exigir que sejam adotados critérios de sustentabilidade ambiental, tanto na extração e fabricação, como na utilização e no descarte dos produtos e matérias-primas, diminuindo, assim, os danos ao meio ambiente.

\section{VANTAGENS E DESVANTAGENS DA UTILI- ZAÇÃO DA SUSTENTABILIDADE NAS COM- PRAS PÚBLICAS}

A utilização dos critérios de sustentabilidade ambiental nas licitações públicas produz algumas possíveis vantagens para o Estado e para a coletividade. Sendo que, proporcionar à sociedade um ambiente ecologicamente equilibrado, limpo e saudável pode ser considerado o principal e mais importante fruto advindo do uso desses requisitos; mantendo, assim, as belezas naturais dos ecossistemas para o proveito das futuras gerações e conquistando uma qualidade de vida melhor para a 
CRITÉRIOS DE SUSTENTABILIDADE AMBIENTAL NA ADMINISTRAÇÃO PÚBLICA FEDERAL: VANTAGENS E DESVANTAGENS COM BASE NA INSTRUÇÃO NORMATIVA 01/2010

população.

Igualmente, um provável benefício advindo pelo uso da Instrução Normativa 01/2010 será a redução dos gastos públicos que, direta ou indiretamente, é gerada quando são aplicadas as práticas de consumo sustentável. De fato, medidas como evitar desperdícios de materiais, reduzir o consumo de água e de energia, entre outras, podem gerar aos cofres públicos uma grande e significativa economia. Destacando-se, ainda, que a redução no consumo desses produtos auxilia demasiadamente na preservação do meio ambiente.

Existem, atualmente, vários procedimentos que a Administração Pública pode utilizar que, além de serem ambientalmente corretos, contribuem para a diminuição dos gastos públicos. A seguir, citam-se alguns deles: usar matéria prima natural renovável e materiais biodegradáveis; adotar coleta seletiva e a destinação final do lixo seco produzido para a reciclagem, destinando parte dos resíduos orgânicos para adubar as plantas de jardins; utilizar meios para diminuir a emissão de substâncias que destroem a camada de ozônio; plantar árvores para compensar parte da emissão de carbono; conservar e usar racionalmente a energia, utilizando lâmpadas que consomem menos energia e com sensor de presença; captar a água da chuva ou reutilizar a água, diminuindo assim o consumo; adotar combustíveis renováveis; utilizar substâncias de ação menos tóxica sobre humanos, animais e plantas reduzindo o risco de contaminação; usar matéria prima pós-consumo e/ou reciclada, etc.

Outras atitudes que merecem ser citadas por sua atual efetivação e por servirem de modelo para outros órgãos e entidades são a virtualização dos processos no judiciário, a disponibilização eletrônica da pauta do dia no Legislativo e a substituição do uso de documentos em papel pelo meio eletrônico, evitando a derrubada de muitas árvores e gerando, do mesmo modo, economia para a Administração.

No executivo, pode-se citar a implantação do Sistema Eletrônico de Informações - SEI, pelo Ministério do Planejamento. Segundo informações do site Portal Brasil, o SEI tem como objetivo a redefinição do modelo de trabalho promovendo a eficiência da gestão e economia para os cofres públicos. Os primeiros dados, indicados com a criação desse projeto, apresentam que:

Somente na Secretaria de Gestão Pública, a Segep, estima-se uma redução de $68 \%$ os gastos com papel; em $62 \%$ os gastos com impressão; e em $55 \%$ o custo com o aluguel de equipamentos de impressão. Além disso, boa parte do gasto com o material de montagem dos processos, como capas e grampos também será reduzido. Com a implantação do SEI, o tempo médio da gestão de documentos e processos será reduzido em 90\%. [...] O projeto já envolve mais de 40 órgãos federais, estaduais e municipais e a estimativa é que a economia de pessoal, equipamentos e papel gire em torno de R \$ 1 bilhão já neste primeiro ano de implantação, se mantidos os patamares alcançados com os projetos-piloto (SISTEMA...

A economia ao serem utilizados esses procedimentos, por exemplo, pode chegar a duas toneladas por mês no consumo de papel somente com a substituição da impressão da ordem do dia do Senado por sua disponibilidade no meio eletrônico, conforme dados apresentados no programa Senado Verde, disponibilizado no portal "Contratações Públicas Sustentáveis" do Ministério do Planejamento (TAJRA, 2012). Demonstrando, dessa maneira, que a redução nos gastos pode ser real e em curto prazo. Já com as obras sustentáveis ocorre de maneira diversa, nelas serão necessário um período maior de tempo para se verificar a economia alcançada; mesmo assim, é muito importante o uso desses critérios nas aquisições de bens e nas contratações de serviços ou de obras, tanto para a sociedade quanto para o Planeta.

Com referência ao preço dos produtos ambientalmente corretos, alguns estudiosos do tema afirmam que uma das desvantagens da utilização de critérios de sustentabilidade nas licitações públicas é que as aquisições de produtos com essas características os tornam mais caros, devido às exigências mais complexas para sua elaboração e processamento. Entretanto Santos (2010a) combate esse posicionamento ao afirmar que:

\footnotetext{
Produtos, serviços e obras de menor impacto ambiental, ainda que tenham um custo aparentemente maior no momento da contratação, são mais baratos no médio e longo prazo. Isso porque reduzem os gastos com políticas de reparação de danos ambientais, têm maior durabilidade e gastam menos energia. Além disso, também incentivam o surgimento de novos mercados e empregos em uma área que ganhará cada vez mais espaço no cenário nacional e mundial daqui para frente.
}

Nesse mesmo sentido, Braga e Coissi (2009, p. 6) acrescenta que: "Os custos de aquisição são apenas uma parte de todos os custos que uma autoridade paga por um produto. Os custos de manutenção, operação e deposição final podem ser maiores do que o esperado." Realmente, o custo com a eliminação dos resíduos de produtos que tenha menor embalagem, ou que sejam facilmente reciclados ou reutilizáveis, será mais baixo do que o descarte de outros que sejam constituídos de material tóxico ou que levem séculos para se decompuser. E, principalmente, é mais barato para os governos preservar o meio ambiente, evitando os possíveis danos, do que repará-los posteriormente. 
CRITÉRIOS DE SUSTENTABILIDADE AMBIENTAL NA ADMINISTRAÇÃO PÚBLICA FEDERAL: VANTAGENS E DESVANTAGENS COM BASE NA INSTRUÇÃO NORMATIVA 01/2010

A título de exemplo, cita-se o trecho do texto "Destruição de recursos naturais causa perdas de US\$2,5 tri ao ano, diz estudo", (DESTRUIÇÃO... 2010) que alerta sobre a necessidade de se incentivar a proteção aos ecossistemas, por exemplo, por meio de prêmios àqueles que protegem a natureza. De fato, o texto citado faz alusão a um caso ocorrido em Nova York onde donos de terra em uma área montanhosa perto da cidade recebem certa quantia em dinheiro das autoridades locais para que adotem técnicas agrícolas mais avançadas. O objetivo do Governo de Nova York com esses estímulos é:

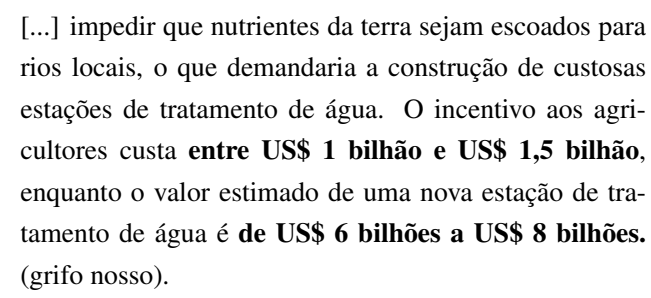

Outro exemplo bem recente que pode ser citado é o caso da cidade de Mariana em Minas Gerais. O rompimento da barragem de Fundão, entre os distritos de Mariana e Ouro Preto, provocou uma onda de lama que devastou os distritos mais próximos, destruiu o Rio Doce, deixou desaparecidos e mortos e poderá afetar ambientalmente as regiões atingidas por muitos anos ainda. "A região de Regência, na foz do rio, é área ambiental protegida por ser considerada berçário para diversas espécies marinhas, em especial tartarugas.”, informa Braga e Coissi (2015). Segunda a jornalista, o meio ambiente poderá nunca se recuperar dos danos sofridos:

\footnotetext{
A previsão é que a enxurrada de lama deverá atingir uma área de $9 \mathrm{~km}$ de mar ao longo do litoral do Espírito Santo, de acordo com um modelo matemático elaborado por pesquisadores da UFRJ (Universidade Federal do Rio de Janeiro). E, embora os impactos no oceano devam ser menos drásticos do que no vale do rio Doce, eles poderão ser duradouros e afetar, por muitos anos, a presença de algas, moluscos, crustáceos e peixes (BRAGA; COISSI 2015).
}

Buscando minimizar os dados ambientais, sociais e econômicos sofridos, diversas ações foram propostas contra a Mineradora Samarco, na tentativa de formar um fundo destinado a ações de melhoria da qualidade ambiental, reparação dos danos das famílias e indenizações. Contudo, a responsabilidade da empresa não isenta a responsabilidade do Estado na fiscalização e na reparação dos prejuízos causados. Quanto aos valores monetários para a reparação dos danos acarretados com esse desastre ambiental, (RAMALHO, 2015) informa que:

Procuradores da União, de Minas Gerais e do Espírito Santos protocolaram nesta segunda-feira (30), na Justiça Federal do Distrito Federal, uma ação civil pública que cobra a criação de um fundo público de $\mathbf{R} \$ \mathbf{2 0}$ bilhões para reparar danos causados pelo rompimento de uma barragem em Mariana (MG), que contaminou com lama a bacia do Rio Doce. [...] Também nesta segunda-feira, a $2^{\text {a }}$ Vara da Fazenda Pública e Autarquias de Belo Horizonte determinou que a mineradora Samarco, cujas donas são a Vale e a BHP Billiton, deposite, em juízo, $\mathbf{R} \$ 1$ bilhão para garantir a reparação dos danos causados pelo rompimento da barragem. Em outra ação desta segunda-feira, desta vez de autoria do Ministério Público, o Tribunal de Justiça de Minas Gerais (TJMG) informou que a Samarco teve R \$ 508.522.538 milhões bloqueados, também como forma de garantir a reparação dos danos. [...] O dinheiro servirá não só para conter problemas imediatos, mas também para repor perdas das famílias atingidas e recuperação do meio ambiente. A aplicação do dinheiro ficará a cargo de órgãos ambientais federal e estaduais. (grifo nosso).

Como se observa, sai mais barato para o Estado evitar um dano ecológico que corrigi-lo num segundo momento, além de que com a valorização das práticas sustentáveis e incentivo do Governo será mais fácil implantar as normas de preservação ambiental existentes. Ademais, a implantação do conceito de sustentabilidade nas compras realizadas pela Administração também gera outras vantagens como: economia em manutenção e operacionalização das edificações (art. $4^{\circ}$, IN 01/2010); redução na produção de resíduos; diminuição dos custos com ações de eliminação ou redução dos danos ambientais, etc.

Do exposto, constata-se que a utilização desses requisitos não aumenta efetivamente o preço dos produtos se considerada a maior durabilidade e melhor eficiência deles, a possibilidade de reciclagem, a diminuição dos gastos com manutenção, etc. Assim, há vantagens na aquisição desses produtos, tanto para a Administração Pública quanto para o meio ambiente.

Salienta-se, ainda, que as contratações públicas que levam em conta a dimensão ambiental servem como exemplo para o setor privado e para a sociedade; ajudam na conscientização quanto à importância da proteção dos ecossistemas; e, da mesma forma, auxiliam na criação de um novo mercado - o dos negócios sustentáveis, pois "os poderes públicos, mediante o fomento da contratação ambientalmente correta, criam verdadeiros 
CRITÉRIOS DE SUSTENTABILIDADE AMBIENTAL NA ADMINISTRAÇÃO PÚBLICA FEDERAL: VANTAGENS E DESVANTAGENS COM BASE NA INSTRUÇÃO NORMATIVA 01/2010

incentivos para que as industriais desenvolvam políticas ambientais voltadas à produção menos impactantes e investimento em tecnologias mais limpas." (BETIOL 2009 , p. 20). Esse novo mercado criará vagas de empregos especialmente nas áreas de pesquisa (necessária para a constante evolução dos produtos, fazendo com que eles cada vez mais interfiram menos no meio ambiente) ou na área de produção, pois a procura por esse tipo de produto ou serviço tende a aumentar, tanto no mercado interno, quanto no externo.

Nesse sentido, no texto "Critérios de sustentabilidade qualificam as compras públicas do país", Santos (2010a) afirma que:

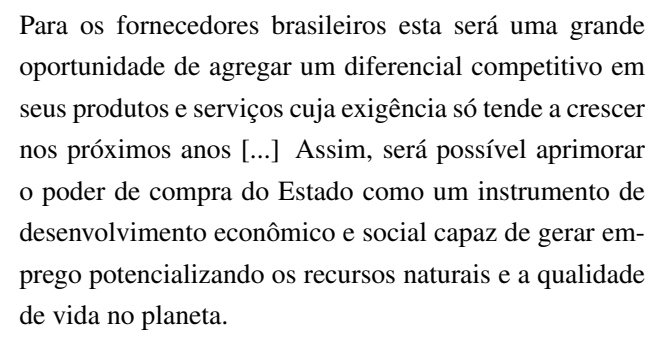

Contudo, cabe evidenciar que tais considerações são baseadas em conhecimentos empíricos e da iniciativa privada, já que no âmbito da Administração Pública Federal a obrigatoriedade da utilização dos critérios de sustentabilidade é relativamente recente, não havendo até o momento estudos estatísticos quanto à efetiva economia alcançada com a utilização de produtos sustentáveis pelos órgãos e entidades do Governo Federal.

De fato, o conceito de sustentabilidade nas compras públicas passou a integrar a Lei 8.666/1993 somente em 2010 por meio de alteração que sobreveio com a Lei 12.349/2010. Com essa lei foi introduzido um novo conceito nas compras públicas que precisava de regulamentação, já que a Administração Pública não estava familiarizada com os critérios de sustentabilidade, as metas, as formas de avaliação e de fiscalização de compras realizadas com critérios sustentáveis.

Assim, em 5 de junho de 2012, surgiu o Decreto 7.746 que regulamentou o art. 3o da Lei no 8.666, de 21 de junho de 1993, para estabelecer critérios, práticas e diretrizes para a promoção do desenvolvimento nacional sustentável nas contratações realizadas pela administração pública federal, e institui a Comissão Interministerial de Sustentabilidade na Administração Pública - CISAP. Esse decreto estabeleceu as diretrizes de sustentabilidade em seu art. $4^{\circ}$, in verbis:

Art. 4o São diretrizes de sustentabilidade, entre outras:

I - menor impacto sobre recursos naturais como flora, fauna, ar, solo e água; II - preferência para materiais, tecnologias e matérias-primas de origem local; III - maior eficiência na utilização de recursos naturais como água e energia; IV - maior geração de empregos, preferencialmente com mão de obra local; V - maior vida útil e menor custo de manutenção do bem e da obra; VI - uso de inovações que reduzam a pressão sobre recursos naturais; e VII - origem ambientalmente regular dos recursos naturais utilizados nos bens, serviços e obras.

E, posteriormente, em 12 de novembro de 2012, foi editada a Instrução Normativa 10 que estabeleceu regras para elaboração dos Planos de Gestão de Logística Sustentável de que trata o art. 16, do Decreto $n^{0} 7.746$.

Desta feita, somente com o advento da IN 10/2012 é que passou a ser obrigatório o uso dos critérios de sustentabilidade pela Administração Pública Federal. Entretanto, para que a Administração elaborasse os Planos de Gestão de Logística Sustentável - PLS foi dado um prazo de vocatio legis de 180 (cento e oitenta) dias contados da publicação da IN 10/2012, ou seja, a Administração teria até 14 de maio de 2013 para se adequar às novas obrigações. Ocorre que em 10 de maio de 2013, esse prazo foi prorrogado por mais 120 (cento e vinte) dias.

Portanto, somente em setembro de 2013, os critérios de sustentabilidade de fato passaram a ser obrigatórios nas compras públicas realizadas pelo Governo Federal. Devido a esse fato, não existem atualmente dados estatísticos quanto à efetiva economia gerada aos cofres públicos pelo uso dos critérios sustentáveis no âmbito da Administração Pública Federal.

Quanto às desvantagens, apesar dos esforços no sentido de esclarecer as dúvidas acerca do tema sustentabilidade nas compras públicas e a despeito de existirem muitas iniciativas nacionais (cursos, palestras, normas diversas, etc) e internacionais (congressos, encontros de gestores, manuais, sites, etc) que buscam explicar o conceito e a aplicação dos critérios ambientais nas licitações, pode-se afirmar que esse assunto, por ser relativamente novo, é um tema de difícil compreensão e encontra algumas possíveis desvantagens na sua implantação.

Primeiramente, como já dito, o custo inicial mais caro dos produtos ambientalmente corretos é considerado, por alguns estudiosos do tema, como uma desvantagem à aplicação da IN 01/10. Nesse sentido, se for levado em consideração somente o preço do produto, este será de fato considerado caro, mas numa visão mais abrangente o produto terá um bom custo-benefício, é o que afirma Silva (2012) a seguir:

No que toca ao preço, recomenda-se que não seja realizada uma análise reducionista, ou seja, apenas do preço. Aplicar o conceito de sustentabilidade nas contratações 
CRITÉRIOS DE SUSTENTABILIDADE AMBIENTAL NA ADMINISTRAÇÃO PÚBLICA FEDERAL: VANTAGENS E DESVANTAGENS COM BASE NA INSTRUÇÃO NORMATIVA 01/2010

significa conciliar as variáveis econômicas, ambientais e sociais de todo o processo. Inclusive, o Princípio da Eficiência deve ser aplicado com um enfoque mais abrangente, levando em consideração também a eficiência ambiental, por exemplo.

Nesse mesmo sentido CYPRESTE (2013, p. 19 apud COSTA 2010) declara que:

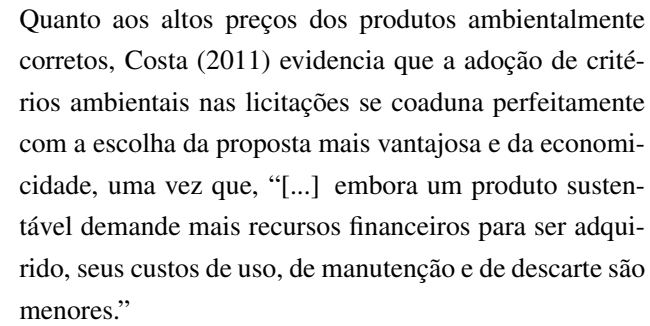

Quanto aos altos preços dos produtos ambientalmente corretos, Costa (2011) evidencia que a adoção de critérios ambientais nas licitações se coaduna perfeitamente com a escolha da proposta mais vantajosa e da economicidade, uma vez que, "[...] embora um produto sustentável demande mais recursos financeiros para ser adquirido, seus custos de uso, de manutenção e de descarte são menores."

Ademais, a falta dos próprios produtos sustentáveis ou de fornecedores deles no mercado pode ser entendida, também, como desvantagem à introdução dos critérios de preservação ambiental nas licitações públicas. Outro ponto muito debatido é a qualidade dos produtos reaproveitados ou reciclados. Outrossim, a exigência de requisitos ambientais nos instrumentos convocatórios pode tornar os procedimentos licitatórios desertos ou fracassados, devido ao despreparo do mercado, o que não seria vantajoso para a Administração.

Do mesmo modo, as desvantagens podem se manifestar por meio de obstáculos que deverão ser transpostos para que sejam implantadas as normas de proteção ambiental. De fato, para a admissão das práticas de consumo sustentável no cotidiano do Poder Público será necessário muito trabalho e mudanças nos procedimentos atuais; observando-se que muitos servidores, e mesmo alguns gestores, não estão acessíveis a tais alterações. Assim, os principais obstáculos à implantação da Instrução Normativa em estudo são: as dificuldades na elaboração das especificações dos produtos em consonância com o estabelecido nas normas; a indisponibilidade no mercado de produtos sustentáveis ou produção em pequena escala; a falta de vontade política de realizar estudos sobre o assunto e divulgá-los; a dificuldade na comprovação de que os bens apresentados pelos fornecedores atendem aos requisitos da IN 01/2010; e a falta de incentivos do Governo para estimular a mudança de comportamento, como, por exemplo, auxiliar no esclarecimento de eventuais dúvidas na elaboração dos Planos de Gestão de Logística Sustentável, disponibilizar modelos ou atribuir orçamento extra aos órgãos para a criação e implementação de projetos que incentivem as iniciativas ambientais.

Igualmente, salienta-se que os procedimentos licitatórios que utilizam critérios de sustentabilidade am- biental não estão isentos de pedidos de esclarecimento (art. 19, Decreto $\mathrm{n}^{\circ}$ 5.450/05) por empresas que não fabricam produtos com essas características; e muito menos estão livres de impugnações (art. $41, \S 1^{\circ}$, da Lei 8.666/93) ao Instrumento Convocatório, tendo por base a ofensa ao princípio da isonomia entre os licitantes, ao princípio da competitividade e até mesmo aos da legalidade e da impessoalidade. Inclusive, recursos administrativos ou judiciais, como mandado de segurança com pedido de liminar, poderão ser interpostos, atrasando dessa maneira o trâmite dos processos até que se tenha uma decisão final sobre o pedido.

Assim, para evitar interferências ao procedimento licitatório como as mencionadas, seria necessária a criação de uma lei especifica que regulasse as compras públicas sustentáveis e que buscasse esclarecer os pontos divergentes que existem. Atualmente, existe vasta legislação infraconstitucional que trata de maneira isolada das várias espécies de sustentabilidade (ambiental, social e econômica). Algumas dessas leis são: a Lei 6.938/1981 que Dispõe sobre a Política Nacional do Meio Ambiente, seus fins e mecanismos de formulação e aplicação, e dá outras providências; a Lei $n^{0}$ 7.754/1989 que estabelece medidas para proteção das florestas existentes nas nascentes dos rios; a Lei $n^{0}$ 9.605/1998 que dispõe sobre as sanções penais e administrativas derivadas de condutas e atividades lesivas ao meio ambiente; a Lei $n^{\circ} 10.295 / 2001$ que dispõe sobre a Política Nacional de Conservação e Uso Racional de Energia; a Lei n ${ }^{0}$ 12.187/2009 que institui a Política Nacional sobre Mudança do Clima - PNMC e dá outras providências e a Lei 12.305/2010, que Institui a Política Nacional de Resíduos Sólidos; altera a Lei no 9.605, de 12 de fevereiro de 1998; e dá outras providências, entre outras.

Entre os decretos que tratam do tema, pode-se citar: o Decreto $n^{\circ}$ 563/1992 que institui o Programa Piloto para a Proteção das Florestas Tropicais do Brasil e cria a Comissão de Coordenação, o Decreto no ${ }^{\circ}$ 2.783/1998 que dispõe sobre proibição de aquisição de produtos ou equipamentos que contenham ou façam uso das Substâncias que Destroem a Camada de Ozônio - SDO, pelos órgãos e pelas entidades da Administração Pública Federal direta, autárquica e fundacional e o Decreto $\mathrm{n}^{\mathrm{o}}$ 5.940/2006 que institui a separação dos resíduos recicláveis descartados pelos órgãos e entidades da administração pública federal direta e indireta, na fonte geradora, e a sua destinação às associações e cooperativas dos catadores de materiais recicláveis, entre outros.

No entanto, não há uma lei de âmbito federal que oriente os Estados e Municípios acerca da aplicação dos requisitos de sustentabilidade nas licitações públi- 
CRITÉRIOS DE SUSTENTABILIDADE AMBIENTAL NA ADMINISTRAÇÃO PÚBLICA FEDERAL: VANTAGENS E DESVANTAGENS COM BASE NA INSTRUÇÃO NORMATIVA 01/2010

cas, apesar da Carta Magna prevê no art. 24, inc. VI que compete à União, aos Estados e ao Distrito Federal legislar concorrentemente sobre proteção do meio ambiente e controle da poluição. Sendo a União responsável por legislar sobre normas gerais; e os Estados e o DF sobre normas suplementares $\left(\S \S 1^{\circ}\right.$ e $2^{\circ}$, art. 24 , da CF).

De igual modo, é importante que a divulgação das atuais campanhas de esclarecimento e de conscientização sobre a relevância do tema atinja seu público alvo, qual seja, a sociedade, os fornecedores e os servidores que atuam na área, sendo indispensável o treinamento desses últimos, pois a falta de conhecimento e treinamento pode ser considerada como obstáculo à incorporação dos requisitos de redução dos impactos ambientais.

Principalmente quanto aos servidores públicos, as notícias/dados encontram-se disponíveis nos sítios oficiais do Governo, contudo as informações disponíveis não são de fácil compreensão, nem de fácil acesso. Assim, seria interessante o desenvolvimento de um projeto que realizasse a capacitação de todos os servidores públicos, in loco, mesmos os indiretamente afetados com as medidas, para o esclarecimento de eventuais dúvidas e auxílio na elaboração dos planejamentos das práticas de sustentabilidade e racionalização de gastos e processos na Administração. Nesse sentido, a revista Negócios Públicos (2009a, p. 6) dispõe que: "Além da conscientização dos líderes acerca da importância de políticas públicas sustentáveis, o conhecimento prático de como aplicar essa gestão também é um desafio".

Como se observa, a falta de conhecimento e treinamento constitui uma das desvantagens/obstáculos à incorporação dos requisitos de redução dos impactos ambientais. Esse também é o entendimento do secretário paranaense de obras públicas, o engenheiro civil Julio César de Souza Araújo Filho, que em entrevista à revista Negócios Públicos (2009b, p. 32-33) faz referência a necessidade de treinamento para os servidores que trabalham na área técnica e para os que exercem a fiscalização das obras sustentáveis. O secretário afirma que:

A correta destinação dos resíduos sólidos da construção civil nas obras sob nossa responsabilidade é uma preocupação constante, tanto que estamos capacitando servidores da área técnica e da fiscalização para coordenar as ações de sustentabilidade nos canteiros de obras, a fim de exigir dos empreiteiros ações concretas para atenuar o impacto ambiental gerado pelo setor e consolidar uma prática de sustentabilidade nas obras públicas. (grifo nosso)
Outro obstáculo à efetivação da IN 01/2010 nos órgãos e entidades é o desconhecimento dos fornecedores sobre o assunto em estudo. De fato, a carência no mercado de produtos classificados como sustentáveis se justificam ora pelo não conhecimento dos fornecedores acerca das novas exigências do mercado, ora por não compreenderem as normas baixadas ou, até mesmo, por terem se acomodado na situação em que estão e, por isso, não buscam se atualizar ao novo mercado. Portanto, os fornecedores também devem conhecer bem o tema e serem incentivados pelo Governo, pois as mudanças que estão ocorrendo nas licitações públicas os afeta diretamente, visto que terão que adaptar sua produção às atuais práticas de consumo sustentáveis. É, nesse sentido, a orientação de texto contido no portal de compras do Governo Federal - o Comprasnet (CRITÉRIOS..., 2010) quando alerta que: "Essas regras vão exigir uma readequação do mercado, já que nem todos os fornecedores terão produtos qualificados para as nossas exigências."

De todo o exposto, torna-se claro que a responsabilidade dos gestores públicos não se limita a aplicação das normas. Eles devem realizar estudos mais aprofundados sobre o assunto, principalmente após a obrigatoriedade da implementação das medidas, para saber se os órgãos estão cumprindo as metas estabelecidas e quais os benefícios e os desafios advindos com os processos sustentáveis. Os estudos até agora apresentados são esparsos, por órgãos, devido à apresentação do PLS só se tornar obrigatório a partir de 2013, não existindo um levantamento geral da Administração Pública Federal acerca do assunto. Apesar do art. 13 da IN 10/2012 determinar que os resultados alcançados a partir da implantação das ações definidas no PLS deveriam ser publicados semestralmente no site dos respectivos órgãos ou entidades, apresentando as metas alcançadas e os resultados medidos pelos indicadores. Ademais, o Governo Federal deveria procurar uma forma de divulgação dos referidos estudos que abordasse de modo mais abrangente e clara possível o público envolvido, além de incentivar a mudança de comportamento, assegurar a livre concorrência e buscar atingir aos interesses da coletividade na preservação do meio ambiente.

\section{CONSIDERAÇÕES FINAIS}

A introdução de práticas de consumo sustentáveis nos procedimentos licitatórios da Administração $\mathrm{Pu}$ blica Federal, por meio da Instrução Normativa 01, de 19 de janeiro de 2010, baixada pelo Ministério do Planejamento, Orçamento e Gestão, em cumprimento ao disposto no art. 28, do anexo I, do Decreto $n^{0}$ $7.063 / 2010$, significa um importante passo da legislação 
CRITÉRIOS DE SUSTENTABILIDADE AMBIENTAL NA ADMINISTRAÇÃO PÚBLICA FEDERAL: VANTAGENS E DESVANTAGENS COM BASE NA INSTRUÇÃO NORMATIVA 01/2010

ambiental, ao relacionar práticas sustentáveis às compras públicas. A IN 01/2010 traz alguns critérios de sustentabilidade que auxiliam na redução dos impactos ambientais, tanto na contratação de obras e serviços, quanto na aquisição de bens, trazendo um rol exemplificativo de requisitos ecologicamente corretos, podendo outros serem estabelecidos conforme surjam novas tecnologias que ajudem na preservação do meio ambiente. No entanto, apesar de representar um avanço, muito ainda deve ser feito para se alcançar o ideal em termos de proteção ambiental.

A IN 01/2010 é o primeiro passo para ser desenvolvida uma política que vise à preservação dos ecossistemas. E para que a legislação continue progredindo nesse campo, sugere-se que uma lei federal específica, que estabeleça normas gerais e oriente todos os órgãos e entidades a realizarem suas licitações com o menor impacto ambiental possível, seja criada para regulamentar as compras públicas sustentáveis, na tentativa de esclarecer as omissões e os pontos divergentes que ainda existem.

Em suma, conclui-se que, a utilização dos critérios de sustentabilidade ambiental nas licitações públicas traz muitas vantagens para o Estado e para a coletividade, como a redução dos gastos públicos e a melhoria da qualidade de vida. No entanto, apesar dos esforços no sentido de esclarecer as dúvidas acerca do tema, este ainda continua de difícil compreensão e encontra desvantagens e obstáculos para sua implantação, por exemplo, muitos fornecedores, servidores e até setores da sociedade ainda desconhecem essa nova tendência mundial de proteção ao Planeta. Observando-se, ainda, que a mudança dos comportamentos e a quebra dos paradigmas existentes não são uma tarefa fácil. Por isso, deverá ser realizada ampla divulgação nos meios oficiais e, do mesmo modo, palestras ou seminários que esclareçam as dúvidas e as incertezas, para que as ideias de preservação ambiental sejam corretamente introduzidas nos órgãos e nas entidades públicas; sendo, assim, absorvidas por todos.

\section{REFERÊNCIAS}

ALENCASTRO, M. S. C. Ética e meio ambiente: construindo as bases para um futuro sustentável. Curitiba: InterSaberes, 2015.

BETIOL, L. As compras públicas sustentáveis: e o desafio de conter as mudanças climáticas. negócios públicos: informações, oportunidades \& poder government businesses connection. 2009.

BIDERMAN, R.; MACEDO, L. S. V. d.; MONZONI, M.; MAZON, R. Guia de compras públicas sustentáveis: uso do poder de compra do governo para a promoção do desenvolvimento sustentável. 2008.

BRAGA, F.; COISSI, J. Incentivar a inovação e a eficiência energética através das compras: um guia prático para autoridades públicas. 2009. Disponível em: <http://www.smart-spp.eu/fileadmin/template/ projects/smart_spp/files/Guidance/SmartSPP_Guide FINAL_pt.pdf>

Lama de Mariana chega ao litoral do ES com protesto de moradores. 2015. Disponível em: <http://www1.folha.uol.com.br/cotidiano/2015/11/ 1709414-lama-de-mariana-chega-ao-mar-do-es-। com-protesto-de-moradores.shtml>

CUNHA, B. P. da; AUGUSTIN, S. Sustentabilidade ambiental: estudos jurídicos e sociais. 2014.

CYPRESTE, A. S. T. Licitações Sustentáveis Instrumento Legal de Promoção da Sustentabilidade:

Um Estudo da Aquisição de Bens na Universidade

Federal do Espírito Santo UFES. Dissertação

(Mestrado) - Universidade Federal do Espírito Santo, 2013.

DESTRUIÇÃO de recursos naturais causa perdas de US\$ 2,5 tri ao ano, diz estudo. 2010. Disponível em: <http://oglobo.globo.com/mundo/mat/2010/10/20/ destruicao-de-recursos-naturais-causa-perdas-de-us- 1 2-5-tri-ao-ano-diz-estudo-922832274.asp>

DIÁLOGO de Desenvolvimento Sustentável Brasil: Compras sustentáveis no Reino Unido. 2010. Disponível em: $<$ http://cpsustentaveis.planejamento.gov.br/noticias/ dialogo-de-desenvolvimento-sustentavel-brasil-। compras-sustentaveis-no-reino-unidol>

FERREIRA, A. B. d. H. Novo dicionário da língua portuguesa. : Nova Fronteira, 1986.

FILHO, M. J. Comentários à lei de licitações e contratos administrativos. : Dialética, 2010.

INFORMATIVO sustentável: Contratações Governamentais com Critérios de Sustentabilidade. 2012. Disponível em: <http://www.comprasgovernamentais. gov.br/gestor-de-compras/sustentabilidade/ compras-sustentaveis>

MELO, C. A. B. de. Curso de direito administrativo. 27. ed. São Paulo: Malheiros, 2010.

RAMALHO, R. União, MG e ES cobram $R \$ 20$ bi de mineradoras por desastre em Mariana: ação 
CRITÉRIOS DE SUSTENTABILIDADE AMBIENTAL NA ADMINISTRAÇÃO PÚBLICA FEDERAL: VANTAGENS E DESVANTAGENS COM BASE NA INSTRUÇÃO NORMATIVA 01/2010

civil propõe fundo a ser alimentado por 10 anos para reparar danos. Procurador diz que objetivo não é quebrar Samarco, Vale e BHP Billiton. Brasília: [s.n.], 2015. 2015. Disponível em: <http://g1.globo.com/minas-gerais/noticia/2015/11/ uniao-minas-e-es-querem-r-20-bi-de-mineradoras- $I$ por-desastre-em-mariana.html>

SACHS, I. Estratégias de transição para o século xxi. Para pensar o desenvolvimento sustentável. São Paulo: Brasiliense, p. 29-56, 1993.

SANTOS, R. S. dos. Critérios de sustentabilidade qualificam as compras públicas do país. 2010. Disponível em: <http://www.planejamento.gov. br/assuntos/logistica-e-tecnologia-da-informacao/ noticias/artigo-do-secretario-da-slti>.

. Guia de compras públicas sustentáveis para Administração Federal. 2010. Disponível em: <www.gespublica.gov.br/biblioteca/pasta.2013-03-28. 9924370611/Guias\%2520de\%2520Compras\% 2520Publicas\%2520Sustentaveis\%2520para\% 2520APF.pdf+\&cd=1\&hl=pt-BR\&ct=clnk\&gl=br>

SILVA, R. C. da. Compras compartilhadas sustentáveis. 2012. Disponível em: <http: //www.comprasgovernamentais.gov.br/paginas/artigos/ compras-compartilhadas-sustentaveis $>$

SISTEMA eletrônico de informação é implantado, year $=2015$, url $=$ http://cpsustentaveis.planejamento.gov.br/noticias/oprograma-senado-verde 1 , urldate $=2015-12$.

TAJRA, H. F. O programa senado verde. 2012.

Disponível em: <http://cpsustentaveis.planejamento. gov.br/noticias/o-programa-senado-verde1> 